\title{
Hacia unA TEORía liberal del CASTigo: \\ LOCKE, PROPIEDAD E INDIVIDUALISMO*
}

Towards a Liberal Theory of Punishment:

Locke, Property and Individualism

\author{
ALFONSO DONOSO \\ Pontificia Universidad Católica de Chile
}

\begin{abstract}
RESUMEN
A partir del análisis crítico de la teoría y propuesta de justificación del castigo penal de Nicolás Maloberti, este artículo avanza una serie de principios y consideraciones que cualquier teoría liberal y lockeana del castigo debe tomar seriamente. Este artículo argumenta que la concepción del estado de Locke -una institución fundada parcial pero significativamente en el derecho a castigar a quien viole derechos naturales- $y$ el carácter básico del derecho a la propiedad dentro de ese esquema de derechos naturales, son elementos que deben llevarnos a afirmar que cualquier teoría genuinamente liberal del castigo no puede prescindir del carácter político del derecho a castigar.
\end{abstract}

Palabras clave: Teoría liberal del castigo, Locke, derecho a la propiedad, Maloberti.

\begin{abstract}
By offering a critical analysis of Nicolás Maloberti's recent theory and justification of punishment, this article accounts for a series of principles and considerations that any liberal and Lockean theory of punishment must take seriously. Indeed, this article contends that Locke's conception of the state -an institution grounded on the right to punish violators of natural rights-and the basic character of the right to property within that scheme of rights, are elements that should lead us to affirm that no genuine liberal theory of punishment can dispense with the political character of the right to punish.
\end{abstract}

Key words: Liberal theory of punishment, Locke, right to property, Maloberti.

* $\quad$ Mis agradecimientos a John D. Charney y dos evaluadores anónimos de RCP por sus valiosos comentarios. Parte importante de este artículo es resultado de mi proyecto Fondecyt Postdoctoral No 3120155. 


\section{INTRODUCCIÓN}

En el Segundo Tratado sobre el Gobierno Civil, Locke afirma que una de las razones más importantes por las que Dios nos ha dado el Estado es evitar algunas de las dificultades que el derecho a castigar presenta en circunstancias prepolíticas (e.g., capítulo 2, §13). ${ }^{1}$ Desde esta perspectiva, nuestra reflexión general acerca del castigo es una reflexión fundamentalmente política: el Estado es el resultado tanto de la autoridad que se le entrega al soberano para imponer cargas punitivas sobre quienes violan la ley legítima de la sociedad política, como del reconocimiento por parte del individuo de las ventajas de renunciar al derecho de imponer tales cargas. ${ }^{2}$ Locke, en efecto, es fuente insoslayable para dar cuenta de la importancia del castigo en la articulación de la concepción liberal de la autoridad política. Asimismo, la propuesta de Locke es relevante para el análisis de las dificultades y posibles soluciones que debe enfrentar cualquier teoría normativa del castigo. Los problemas de la proporcionalidad, propósito y justificación del castigo son cuestiones ineludibles en el análisis sobre la práctica punitiva por parte del Estado y todas ellas ocupan un lugar importante e iluminador en el Segundo Tratado. Por todo esto hacemos bien en volver a Locke cuando lo que nos interesa es ofrecer una teoría general del castigo. Por todo esto hacemos bien en volver a Locke cuando lo que nos interesa es ofrecer una teoría liberal del castigo.

En un artículo recientemente publicado en esta revista, ${ }^{3}$ Nicolás Maloberti hace eco de lo anterior y nos promete una teoría del castigo "más congruente con las premisas individualistas de la tradición lockeana que la concepción del castigo que podemos encontrar en el mismo Locke, como así también en otros autores cercanos a esa tradición, como Grocio y Robert Nozick" (Maloberti, 2011: 31). En este artículo me interesa poner en cuestión el cumplimiento de esa promesa. Mi objetivo no es cuestionar el uso de la concepción del castigo de Locke en orden a ofrecer una teoría lockeana del castigo que sea más coherente, plausible y exitosa que la del mismo Locke. En lugar de eso me propongo poner en duda el carácter lockeano de la teoría propuesta por Maloberti.

Independientemente del uso de categorías lockeanas para formular una teoría del castigo, una teoría genuinamente lockeana del castigo debe ser sensible al espíritu del pensamiento político de Locke. Una de mis conclusiones es que la propuesta de Maloberti no captura ese espíritu.

Sin embargo, este es un cuestionamiento que, aun si fuese exitoso, podría no representar una dificultad concluyente para quien se aboca a ofrecer una teoría del castigo que sea en sí misma más competente que otras teorías posibles. En respuesta a mi objeción, le bastaría a Maloberti decir que su propuesta es primero una teoría del castigo y después,

$1 \quad$ Utilizo la versión de Ian Shapiro del Segundo Tratado de Locke en Locke, J. (2003) Two Treatises of Government and A Letter Concerning Tolerance. I. Shapiro (ed.) (London: Yale University Press). En adelante, ST seguido del número del capítulo y la sección correspondiente. Todas las traducciones son mías.

Evidentemente, ésta es solo parte de la justificación del Estado según Locke.

Maloberti, N. (2011). “Disuasión y Castigo desde una Perspectiva Lockeana”, Revista de Ciencia Política 31 (1): 29-46. 
sólo secundariamente, una teoría lockeana del castigo. Concediendo esa posibilidad, mi objetivo en este artículo va más allá de la objeción recién presentada. Además de objetar el carácter lockeano de la teoría que Maloberti nos presenta me interesa rechazar la coherencia, conveniencia y, quizás, la plausibilidad misma de una teoría del castigo como la que Maloberti avanza. En efecto, del análisis desarrollado en este artículo se sigue que el conjunto posible de teorías liberales del castigo no debiera incluir la teoría del castigo que Maloberti defiende.

El artículo se organiza del siguiente modo. La segunda parte presenta brevemente el argumento general de la teoría de Maloberti (sección i) y da cuenta de mi primera objeción, según la cual esta teoría no es consistente con el espíritu de la propuesta de Locke, por lo que malamente podríamos calificarla como una concepción lockeana del castigo (sección ii). La tercera parte presenta la segunda objeción, en la que cuestiono la coherencia y conveniencia de la teoría de Maloberti (objeciones tipo I y II). Tomadas en conjunto, estas objeciones representan una línea argumental negativa que, por contraste, deja entrever la dirección general que debiera adoptar cualquier teoría liberal del castigo.

\section{LOCKE Y EL DERECHO A CASTIGAR}

\section{i. Maloberti y el Derecho Natural a Castigar}

El punto de partida de Maloberti es la tesis lockeana según la cual los individuos son sujetos de derechos existentes independientemente de cualquier convención, acuerdo, o acción. En otras palabras, los sujetos poseen derechos naturales. Uno de esos derechos naturales, quizás el más fundamental para Locke, es el derecho de propiedad. Este derecho es sobre nuestra propia persona y las cosas del mundo adquiridas de acuerdo a reglas de apropiación adecuada (véase ST 5). Siguiendo un argumento de Eric Mack, Maloberti afirma que todo este interés por la propiedad busca articular un principio fundamental del liberalismo de Locke, a saber, "que las personas deberían ser libres de vivir sus propias vidas de acuerdo a sus propias elecciones" (Maloberti, 2011: 32).

Un primer momento clave en el artículo de Maloberti ocurre cuando afirma que, puesto que tales derechos a la propiedad -sobre nuestros cuerpos y cosas externas adecuadamente apropiadas- son derechos naturales de propiedad (DNP), los individuos "deben tener también control exclusivo sobre ciertas acciones coactivas que son necesarias para asegurar dicho control sobre los recursos materiales [sobre sus cuerpos y recursos externos adecuadamente apropiados]" (Maloberti, 2011: 33). Estas acciones coactivas sobre las cuales los individuos deben tener control exclusivo para hacer respetar DNP son articuladas en términos de ciertos derechos naturales de enforcement (DNE). A su vez, las acciones que constituyen DNE son acciones de tres tipos, dependiendo de si ellas pueden localizarse en un tiempo anterior, presente, o posterior a la violación de DNP. Maloberti determina el primer tipo de acción constituyente de DNE a partir de un derecho a formular amenazas ante la eventual violación futura de DNP. El segundo tipo de acción corresponde al derecho de defensa propia durante la violación de DNP y el tercer tipo de acción corresponde al derecho a obtener restitución tras la violación 
de DNP. Todos estos derechos, dice Maloberti, generalmente no son cuestionados y es difícil que puedan ser negados convincentemente.

Adicionalmente, y siguiendo en esto a Locke (ST 2.7-12), Maloberti afirma que dentro de DNE debemos incluir el derecho natural a castigar (DNC) adecuadamente limitado (ver, por ejemplo, ST 2.8 y 7.87). Efectivamente, si no fuese legítimo utilizar nuestro poder para protegernos de quien viola nuestros derechos fundamentales, en vano podríamos afirmar la ley fundamental de la naturaleza que ordena nuestra propia preservación. Sin embargo, y ahora distanciándose de Locke, Maloberti afirma que DNC debiera justificarse en términos semejantes a los otros tres DNE considerados. Tradicionalmente -como bien ve Maloberti- la diferencia entre DNC y los otros derechos contenidos en DNE se establece porque el primero no es un derecho exclusivo de la víctima: "cualquier hombre tiene el derecho de castigar al ofensor y volverse ejecutor de la ley natural" (ST 2.8). ${ }^{4}$ En contraste con esta visión tradicional, Maloberti afirma que -éste es, en mi opinión, el segundo momento clave del artículo- "[e]l derecho a castigar podría justificarse sobre las mismas preocupaciones de seguridad individual que nos llevan a justiciar los otros derechos de enforcement" (Maloberti, 2011: 37). Para Maloberti, esta justificación sería no solo más coherente con las premisas individualistas de la tradición lockeana sino también más convincente vis-à-vis otras teorías tradicionales del castigo.

Distintas razones justifican este segundo momento clave. Maloberti echa mano al importante y sofisticado trabajo de Warren Quinn, "The Right to Threaten and the Right to Punish", según el cual el derecho a castigar deriva de un derecho del individuo a amenazar al (potencial) agresor con anterioridad a la (potencial) violación de los derechos del individuo (y en orden a disuadir al (potencial) agresor de cometer esa violación. En otras palabras, en orden a disuadir al posible violador de mis derechos, yo tengo el derecho a crear un estado de cosas tal que asegure razonablemente que mi potencial agresor reciba algún tipo de carga dañosa tras violar mis derechos. Este derecho a imponer cargas dañosas derivado de mi derecho a amenazar, afirma Quinn, es semejante al derecho de castigar.

El resultado de esta justificación del castigo es una teoría mixta que combina elementos retrospectivos -la comisión de una violación por un ofensor- y elementos prospectivos -la protección de un individuo de potenciales violaciones. Maloberti considera que esta teoría mixta del castigo debe ser celebrada pues recoge lo mejor de dos mundos: por una parte, se hace cargo del reconocimiento moral de la instrumentalidad del castigo (una

4 En este punto Maloberti hace referencia a Locke y Grocio. Vale la pena quizás subrayar que esta diferencia entre DNC y otros derechos incluidos en DNE es también central a las concepciones más influyentes de gran parte de la filosofía del derecho penal contemporáneo (véase Duff, 2001; Marshall \& Duff, 1998, Lamond 2007. Para una propuesta clásica véase Blackstone, 1770). De acuerdo a esta concepción, el derecho penal, y con ello, el derecho a castigar, corresponde a un derecho fundamentalmente público, por oposición a un derecho característicamente civil, como lo es, por ejemplo, el derecho a amenazar o el derecho a la restitución (o compensación) (el derecho a la defensa propia supone algunas cuestiones más sutiles que no viene al caso analizar en este ensayo). En Locke, lo que justifica que el DNC de la víctima V en contra del ofensor O por una violación $\phi$ contra $\mathrm{V}$ se extienda a un individuo $\mathrm{J}$ (quien así tiene un DNC contra O por $\phi$ contra $\mathrm{V}$ ) deriva del hecho que "[a]l trasgredir la ley natural [mediante $\phi]$, el ofensor [O], se declara a sí mismo como viviendo bajo una regla distinta a las de la razón y de la equidad común, [...] al hacerlo, se convierte en un peligro para el género humano [un peligro para V, J y otros]" (ST 2.8; véase también ST 2.11). 
virtud consecuencialista) y, por otra parte, hace impermisible el castigo del inocente (una virtud no-consecuencialista).

\section{ii. ¿Una perspectiva lockeana del castigo?}

De lo anterior cabe preguntarse, ¿es ésta-como afirma Maloberti-una perspectiva lockeana del castigo? Asumo que lo que esa afirmación intenta sugerir es que la justificación del castigo que esta perspectiva propone, si bien no es la justificación que Locke mismo avanzó, se funda en consideraciones y principios que son significativamente afines a la tradición que se desprende de Locke. El elemento más característico de esa tradición es el individualismo. Ciertamente alguna forma de individualismo forma parte de la tradición liberal y es innegable que Locke efectivamente representa parte de esa tradición. Sin embargo, lo que me parece errado en la argumentación de Maloberti es la afirmación según la cual ese individualismo liberal y lockeano pueda quedar adecuadamente capturado -y más enfáticamente, deba quedar capturado- a través de la inclusión de DNC dentro del conjunto de derechos naturales de enforcement. Es verdad que 'el derecho a castigar podría justificarse sobre las mismas preocupaciones de seguridad individual que nos llevan a justiciar los otros derechos de enforcement'. Sin embargo, contra Maloberti, quiero defender que si parte de nuestra preocupación es el individualismo liberal y lockeano, entonces DNC no debe justificarse de esa manera. ${ }^{5}$

El individualismo liberal y lockeano solo se comprende dentro de algún marco normativo no convencional. Para utilizar un término general afín a la posición del mismo Locke podemos caracterizar ese marco normativo en términos de derechos naturales. Así, el individualismo liberal y lockeano debe articularse en el marco de ciertos derechos naturales que son condición necesaria de cualquier práctica legítima tanto en condiciones políticas como prepolíticas. Maloberti cree ser fiel a esa tradición al sugerir que DNC sea entendido de una manera semejante a los DNE antes considerados. Al afirmar esto, parece creer Maloberti, no le negamos ilegítimamente al individuo la posibilidad de imponer cargas a quienes violan nuestros DNP; de la misma manera que no debemos negarle a un individuo el derecho a la defensa propia, tampoco podemos negarle a un individuo el derecho a castigar. Afirmar lo contrario sería, primero, negarle al individuo algunos de sus derechos fundamentales y, segundo, reducirle la posibilidad de proteger algunos de esos mismos derechos. Esto, afirmaría Maloberti, es contrario al individualismo liberal lockeano.

Desde la perspectiva defendida en este artículo, esto es errado. La equivocación de Maloberti está en pensar que incluir DNC dentro del conjunto de derechos DNE es compatible con-o incluso exigido por- una teoría lockeana del castigo. Más precisamente, lo que considero

5 Mi referencia a un individualismo liberal y lockeano explicita la cuestión de que hay, en efecto, formas de liberalismo no-lockeano (e.g., el liberalismo igualitario de corte rawlsiano) - la alternativa inversa, en cambio, parece incoherente. Por lo tanto, mi análisis crítico del artículo de Maloberti debe entenderse, a lo menos, como la afirmación de que la teoría del castigo que su propuesta favorece no es liberal y lockeana, lo que deja abierta la posibilidad lógica de que su propuesta sea liberal y no-lockeana. Sin embargo, a partir de lo que elaboro en la tercera parte del artículo, la conclusión que debe sacarse es más fuerte: la teoría del castigo que su artículo defiende tampoco es liberal. Agradezco a un evaluador anónimo de RCP por invitarme a realizar esta precisión. 
un error en la propuesta de Maloberti es la sugerencia de que la naturaleza de DNC es tal que es legítimo asemejar este derecho a los otros derechos que constituyen DNE. Esto no significa negar (ni afirmar) que DNC pueda ser un DNE. En cambio, lo que sí niego es que DNC sea un derecho semejante a los derechos que Maloberti considera como parte de DNE. La tarea de establecer semejanzas entre distintos derechos requiere evidentemente de algún criterio de análisis que nos permita establecer tal comparación. Como los siguientes párrafos de esta sección explican, para los propósitos presentes me gustaría negar que, dentro del contexto de la propuesta de Locke en el Segundo Tratado, DNC sea semejante de modo relevante a los derechos que Maloberti considera en su análisis de DNE.

La combinación de las siguientes dos consideraciones debieran llevarnos a concluir que el derecho natural a castigar no es semejante de modo relevante a los otros derechos de enforcement considerados por Maloberti. Primero, tal y como Maloberti señala, a partir del Segundo Tratado es plausible entender DNC como el resultado de DNP. Sin embargo, a diferencia de lo que Maloberti sugiere, de eso no se sigue necesariamente que DNC tenga el mismo carácter que otros derechos que plausiblemente se derivan de DNP, como los otros derechos que constituyen DNE. Segundo, y como anunciaba al inicio de este trabajo, las consideraciones de Locke con respecto al castigo tienen un carácter fundamentalmente político, en el sentido que son necesarias para la justificación del Estado. De acuerdo a Locke, parte significativa de las dificultades que se derivan de la existencia de DNC en circunstancias no políticas quedan resueltas al renunciar a DNC en circunstancias políticas (ST 2.13; ST 7.87-90). Tal renuncia, en efecto, es condición de lo político (ST 7.89). Maloberti efectivamente reconoce que si bien Locke deriva DNC de DNP, éste no entiende DNC como un derecho del mismo carácter que los derechos que constituyen DNE. Maloberti no se equivoca en esto. Su equivocación proviene, más bien, de desconocer la importancia que esta distinción tiene para Locke y el individualismo de corte lockeano que él mismo intenta defender.

Más allá de una serie de detalles y sutilezas exegéticas, basta decir que el contractualismo lockeano no puede concebirse sino a partir de la importancia normativa fundamental -i.e., de acuerdo a las leyes de la naturaleza- que tiene el respeto a DNP: los poderes del Estado tienen por objeto "la preservación de la propiedad de todos los miembros de dicha sociedad hasta donde sea posible" (ST 7.88). Ahora, y esto es lo que Maloberti desconoce, el respeto a DNP no es sostenible sino mediante la distinción que debe hacerse en la esfera de lo político entre DNC y los derechos constituyentes de DNE. Negar esto es negar la importancia normativa fundamental que DNP posee para Locke. Negar tal cosa es, al final, rechazar un principio lockeano sine qua non, a saber, que el derecho de propiedad sobre nuestro cuerpo y cosas del mundo adecuadamente apropiadas es un derecho básico de los individuos. ${ }^{6}$ Esto está a la base de cualquier individualismo propiamente lockeano. Por el contrario, la

6 La idea de derechos básicos la tomo prestada del análisis de los derechos de Henry Shue. Él dice que "the substance of a basic right is something the deprivation of which is one standard threat to rights generally. The fulfillment of a basic right is a successful defense against a standard threat to rights generally. This is precisely why basic rights are basic. That to which they are rights is needed for the fulfilment of all other rights" (Shue, 1996, p. 34). Es en este sentido que, desde una perspectiva lockeana, el derecho de propiedad es un derecho básico. 
estrategia de Maloberti desafía esa caracterización de DNP. En efecto, al prescindir de la diferencia relevante que existe entre el derecho a castigar y otros derechos constituyentes de DNE, Maloberti cuestiona lo que para Locke es incuestionable, a saber, que el Estado -vía el castigo, entre otras cosas- es indispensable para la protección de la propiedad. ${ }^{7}$

La explicación de este indeseable resultado es la siguiente. En el estado de naturaleza lockeano (aún atendiendo a toda la distancia que existe entre éste y la concepción hobbesiana del mismo) la propiedad no recibe una protección suficiente. En circunstancias no políticas las pasiones humanas nos llevarán más allá de lo que las leyes de la naturaleza permiten: "el amor propio hará a los hombres parciales hacia sí mismos y sus amigos [...], la naturaleza enferma, la pasión y la venganza los arrastrarán demasiado lejos en el castigo que imponen a los demás; y de todo esto solo resultará confusión y desorden" (ST 2.13). Que no se malentienda, en ausencia del Estado la víctima de una violación de DNP efectivamente posee un derecho a responder al violador de tales derechos mediante la imposición de cargas dañosas. Sin embargo, en esas mismas circunstancias, debido a la ausencia de una especificación suficiente de los límites y aplicación de tales cargas -ambigüedad inherente a la descripción del estado de naturaleza- el ejercicio de ese derecho necesariamente deviene en la imposición desproporcionada (se castiga más o menos que lo que la violación y sus circunstancias ameritan) y asistemática (se castiga -o deja de castigar- sin atender a reglas que apliquen de igual manera para violaciones semejantes) de estas cargas. ${ }^{8}$

La inevitabilidad y profundidad de los problemas derivados del ejercicio del derecho privado a castigar son presentados por Locke con claridad cuando afirma que "[l]a finalidad de la sociedad civil es evitar y remediar los inconvenientes del estado de naturaleza que se producen necesariamente cuando cada hombre es juez de su propio caso" (ST 7.90. Mi énfasis). Efectivamente, toda esta desproporción y asistematicidad en la aplicación del castigo es el origen de serias violaciones adicionales en contra de DNP. Si un ofensor viola uno de mis derechos imponiendo una carga ilegítima de magnitud $m$ mi respuesta en contra del ofensor debe corresponder, ceteris paribus, a una carga retributiva razonablemente similar a $m$. Un resultado distinto a $m$ (bien por exceso o bien por defecto) representa una violación de DNP o, al menos, una deshonra a tales derechos. Desde una perspectiva lockeana, ambos resultados son inaceptables. ${ }^{9}$ Uno debe concluir, entonces, que a partir tanto de las exigencias normativas impuestas por las leyes de la naturaleza como de los forzosos inconvenientes que se siguen de ser juez en nuestra propia causa, la constitución de lo político -y con ello la necesaria renuncia al DNC- es una exigencia para la protección y respeto de DNP. Cualquier línea argumentativa que cuestione la renuncia a DNC -al

7 Sería un error asumir que de esto se sigue que el estado liberal de carácter lockeano no tiene que cumplir otras funciones. Lo que estoy presentando aquí debe entenderse como una condición necesaria pero no suficiente del estado liberal lockeano.

8 En estas circunstancias ocurre lo que sucede en muchos contextos de deliberación práctica: aunque reconozco la posesión de un derecho reconozco también que no debo ejercer ese mismo derecho.

9 Es interesante notar la aparente asimetría que existe en este contexto entre una falta por defecto y una falta por exceso. Siguiendo el ejemplo considerado, imponer una carga retributiva menor a $m$ en un grado $(m-1)$ parece implicar una falta menos seria que imponer a la misma violación una carga retributiva mayor a $m$ en un grado $(m+1)$. Para un análisis de este punto véase Hurka, 2003. 
menos desde una perspectiva genuinamente lockeana- representa una amenaza al valor fundamental de la propiedad.

Es importante recalcar que la defensa y justificación del Estado a la que se ve obligado Locke en el Segundo Tratado -así como la concepción del castigo que éste avanza- es justamente el resultado de su individualismo. Dicho de otra manera, es precisamente porque Locke abraza algún tipo de individualismo liberal que una de las consecuencias de su argumento es la instauración de la autoridad política constituida por el derecho a castigar. El individualismo lockeano tiene a la base el derecho fundamental a la propiedad de cada uno consistente con la conservación de la propiedad de todos los demás (e.g., ST 2.6). Ahora, y como ya vimos más, dados los inconvenientes inevitables que conlleva el estado de naturaleza, el ejercicio del DNC en contra de quien viole algún derecho fundamental debe ser limitado a algún tipo de norma pública que interprete y especifique el ejercicio de ese derecho (e.g., ST 2.12). Todo esto en aras precisamente de proteger el derecho individual fundamental a la propiedad: "Por lo tanto, la finalidad máxima y principal que buscan los hombres al unirse en estados, sometiéndose a un gobierno, es la preservación de su propiedad. En el estado de naturaleza esta preservación es muy pobre" (ST 9.124). Puesto que lo que define al estado de naturaleza es la ausencia de una norma pública autoritativa que impida los inevitables excesos del ejercicio de nuestro derecho natural a castigar, quien quiera honrar al individuo y sus derechos más fundamentales (DNP) desde una perspectiva genuinamente lockeana debe aceptar la necesidad y legitimidad de la renuncia a DNC a favor del Estado.

\section{JUSTIFICACIÓN Y MAGNITUD DEL CASTIGO}

De la segunda sección de este trabajo concluyo que la propuesta de Maloberti falla en capturar el individualismo liberal y propiamente lockeano. La idea de que el derecho natural a castigar deba ser entendido como un derecho justificable en términos similares a los de los otros derechos constituyentes del derecho natural de enforcement no toma en serio la importancia fundamental que el derecho a la propiedad tiene para Locke y que le obliga a éste a entender el Estado como la única entidad con la legítima autoridad para castigar. Una teoría que no se hace cargo de este punto no puede autodefinirse como una teoría fundada en una perspectiva lockeana del castigo.

La propuesta de Maloberti, sin embargo, no se reduce simplemente a ofrecer una teoría del castigo en clave lockeana. Su artículo tiene un objetivo más sustancial, a saber, ofrecer una teoría liberal del castigo superior a las teorías alternativas. Así, Maloberti bien podría afirmar que el interés principal de su artículo no es meramente ofrecer una teoría lockeana del castigo sino, además, ofrecer una teoría liberal del castigo que sea superior a las teorías alternativas. Ciertamente no toda teoría liberal del castigo debe ser lockeana, de modo que, prima facie, mi primera objeción no toca necesariamente el carácter liberal de su propuesta. ${ }^{10}$ Sin embargo, por razones de distinta índole-algunas 
de las cuales derivan precisamente del carácter no-lockeano de la teoría de Malobertien lo que sigue intento mostrar que esta teoría del castigo no debe ser abrazada por ninguna teoría liberal. Partamos por dar cuenta más claramente de los principios básicos de aquella teoría.

Aunque Maloberti no desarrolla de manera sistemática los lineamientos de la teoría del castigo que su artículo defiende, es posible entrever algunos de los elementos que la componen. La tesis central de esta teoría del castigo queda expresada en la siguiente afirmación:

(i) El individuo-víctima (IV) de una agresión por parte de un individuo-agresor (IA) tiene la autorización para hacer efectivas sus amenazas de retaliación contra IA porque IA merece la carga que involucra la efectuación/actualización de las amenazas de IV (Maloberti, 2011: 39 y 44).

Lo que justifica la autorización anterior es que:

(ii) La agresión de IA incrementa la vulnerabilidad de IV -criterio justificatorio noconsecuencialista (Maloberti, 2011: 39)

(iii) La negación de esta autorización significa reducir el valor disuasivo del derecho a formular amenazas de retaliación y dificulta la restauración de la credibilidad de IV (Maloberti, 2011: 39) -criterio justificatorio consecuencialista.

Adicionalmente, es reconocible un límite a la autorización en (i), a saber:

(iv) La magnitud legítima de la efectuación de las amenazas de retaliación de IV a IA está limitada por la restitución de la posición estratégica ex ante de IV (i.e., anterior a la transgresión de IA) (Maloberti, 2011: 42).

Presentaré dos tipos de objeciones que, en conjunto, me parecen suficientes para rechazar la teoría de Maloberti. La primera es una objeción vinculada a la coherencia de esta propuesta. La segunda es acerca de la plausibilidad y conveniencia de esta teoría.

\section{i. Objeción tipo I}

La presentación esquemática de los distintos principios, elementos justificatorios y límites de esta teoría del castigo dan cuenta, como implícitamente sugiere Maloberti, de una teoría mixta del castigo. Una teoría mixta del castigo es una teoría que intenta resolver el problema de justificación asociado al castigo mediante la combinación de consideraciones tanto consecuencialistas como no-consecuencialistas. Si seguimos el análisis clásico del castigo de H.L.A. Hart, diremos que el Fin Justificativo General (General Justifying Aim) del castigo son las consecuencias beneficiosas de esta práctica, mientras que el Fin General (General Aim) se restringe al castigo de un ofensor por su ofensa. Dicho de otra manera, para Hart el consecuencialismo y el no-consecuencialismo acerca del castigo son perfectamente consistentes cuando se combinan en una misma teoría porque ambos responden a preguntas distintas. Mientras la pregunta por la justificación general del castigo debe responderse en términos consecuencialistas -por las consecuencias favorables que trae el castigo comparado con otras prácticas alternativas- la pregunta 
acerca de quién debe ser castigado debe responderse en términos no-consecuencialistas -sólo debe castigarse un ofensor por su ofensa (Hart, 2008a).

En contraste con la teoría de Hart, Maloberti elabora una teoría mixta que presenta la justificación general del castigo en términos no-consecuencialistas: la transgresión pasada del agresor hace a éste merecedor de alguna carga impuesta por la víctima vía castigo (según i); la víctima está autorizada a castigar al agresor porque el agresor merece la carga que este castigo significa. Es esto lo que justifica la práctica del castigo. Sin embargo -y según Maloberti en esto radica parte importante de la virtud de su teoría-, esta teoría reconoce también el valor instrumental del castigo: el castigo del ofensor por parte de la víctima reduce la posibilidad de futuras agresiones sobre la víctima y aumenta -o mantiene- su credibilidad (según iii). Asimismo, estos fines consecuencialistas están limitados por la consecución del estado de vulnerabilidad ex ante de la víctima (según iv) y por el castigo de un ofensor por su ofensa (según i). ${ }^{11}$

En general, la propuesta de una teoría del castigo en términos mixtos debe ser celebrada. Parece más que razonable defender la justificación de la práctica del castigo sin olvidarse de una serie de consideraciones tanto consecuencialistas (¿debemos castigar a X cuando de este castigo se sigue más mal que bien?) como no-consecuencialistas (¿debemos castigar a $X$ por todo lo bueno que se sigue de ese castigo aun cuando $X$ no merece ser castigado?). Sin embargo, la elaboración de una teoría mixta no basta para justificar el castigo. Lo que se requiere es una teoría mixta adecuada. En lo que sigue me gustaría mostrar que el principio central de la teoría de Maloberti no puede ser justificado en los términos que él propone. Esto afecta la coherencia que debemos exigir de cualquier teoría adecuada del castigo. ${ }^{12}$ Dicho de otra manera, intentaré mostrar que la verdad de (i) no asegura ni requiere de la verdad de los elementos justificatorios de la teoría, de modo que (i) es independiente de lo que Maloberti sugiere que justifica (i) y esta independencia malogra el rol de justificación de estos elementos.

Consideremos el siguiente ejemplo: Goliat va por la vida amenazando a quien se le cruce: 'Si por cualquier motivo entras en mi propiedad sin mi autorización te descuartizaré. Ni siquiera dudes que lo haré'. Efectivamente las amenazas de Goliat son creíbles -ya ha descuartizado a unos cuantos sujetos que osaron entrar en su propiedad. David, quien no está al tanto de estas amenazas, a media noche entra sin permiso en la casa de Goliat. Cuando David entra en la propiedad, Goliat duerme y no se da cuenta de la presencia del intruso. Durante un par de horas David deambula por la casa, bebe y come lo que

11 Es importante notar que después de la teoría de Hart existen muchas teorías del castigo que pueden ser consideradas teorías mixtas del castigo sin ser teorías mixtas consecuencialistas, como la de Hart. En este sentido, la teoría de Maloberti está acompañada por una conspicua lista de teorías (por lo demás, teorías muy diversas entre sí), como por ejemplo, Duff (2001) y von Hirsh (1993).

12 De lo dicho hasta este lugar podría concluirse que al menos parte de una teoría adecuada del castigo debe atender a consideraciones no-consecuencialista. No es mi intención problematizar este punto y simplemente asumiré que efectivamente la justificación del castigo (al menos una parte de ella) depende de consideraciones no-consecuencialistas. Esto significaría afirmar como verdadero que: 'El castigo impuesto a X por $\phi$ es justificable porque, entre otras consideraciones, $X$ merece ser castigado por $\phi$ ' o 'Que X merezca un castigo por $\phi$ es condición necesaria para que el castigo de $X$ por $\phi$ sea legítimo'. Estas afirmaciones son consistentes con (i) y comparten su espíritu no-consecuencialista. 
hay en el refrigerador, y finalmente entra en la habitación de Goliat. Cuando David ve a este hombre inmenso, decide golpearlo y matarlo con una roca que guarda en su bolsillo. Al golpear a Goliat, David cae en cuenta que la fortaleza de éste es extraordinaria y que sus débiles golpes no son capaces ni siquiera de interrumpir su sueño. Frustrado, David deja la propiedad. Mientras, Goliat duerme plácidamente con solo unos rasguños en el cuerpo producto del ataque de David.

En el ejemplo, una respuesta positiva a la pregunta de si David merece un castigo no es controversial. El ingreso no autorizado en la propiedad de Goliat, el uso sin consentimiento de sus bienes, el intento de homicidio, el daño provocado por el asalto, todas estas son acciones que tenemos muy buenas razones para castigar pues representan actos que, por así decirlo, invitan alguna forma de demérito relevante en el agente. La comisión de cualquiera de ellas sin una excusa o justificación nos hacen merecer la imposición de una carga punitiva. Maloberti, en consistencia con (i), no negaría este punto.

Sin embargo, preguntémonos ahora por qué estas acciones generan demérito en David. Una respuesta es que, de acuerdo a (iii), las amenazas de Goliat dejan de ser disuasivas (o tan disuasivas) tras la acción de David. Sin embargo, esto no es cierto. Las amenazas de Goliat siguen siendo tan verosímiles como antes del evento considerado. El hecho de que Goliat no se haya percatado de la violación a sus derechos es irrelevante, por una parte, para afirmar la existencia de esas violaciones y, por otra, para determinar la supuesta falta de credibilidad de sus amenazas futuras. Asimismo, la credibilidad de las amenazas de Goliat no ha disminuido por el hecho de que la acción de David pasase inadvertida. Ni la fuerza disuasiva ni, consecuentemente, la credibilidad de Goliat y sus amenazas han sido puestas en juego por la acción de David.

Quizás la respuesta esté entonces en (ii) -la acción de David supone un aumento de la vulnerabilidad de Goliat. Sin embargo, esta tampoco parece ser una respuesta plausible; la acción de David en nada aumenta la vulnerabilidad de Goliat (ni ante los ojos de Goliat ni ante los ojos de los demás) -este sigue siendo tan poderoso como antes del evento- aun cuando ésta es una acción que efectivamente genera demérito en David.

Si este análisis es correcto, debemos entonces concluir que la tesis central de Maloberti no se funda necesariamente en el tipo de justificación que él tiene en mente. La autorización de IV para hacer efectivas sus amenazas de retaliación no se halla en ninguna de las justificaciones que es posible entrever en la teoría defendida por Maloberti. Ellas, en consecuencia, deberán buscarse en un lugar distinto.

\section{ii. Objeción tipo II}

Consideremos ahora un segundo tipo de objeción. Aquí voy a afirmar que, por las razones que presento a continuación, aún si fuese capaz de responder a todas las objeciones anteriores, la teoría de Maloberti es una teoría del castigo que no debiéramos adoptar. Esta objeción se concentra en la última determinación (iv) de la teoría delineada anteriormente. Recordemos que (iv) representa un límite o restricción a la autorización presentada en (i), de modo que la magnitud legítima de la ejecución de las amenazas de retaliación de IV a 
IA está limitada por la restitución de la situación estratégica ex ante de IV (i.e., anterior a la transgresión de IA) (ver Maloberti, 2011: 42).

Hay distintas razones por las que me parece inconveniente adoptar una teoría que determina la legitimidad de la magnitud del castigo en términos de la posición ex ante de la víctima. Menciono las que considero más evidentes:

Razón 1: En una gran cantidad de casos penales la magnitud del castigo se determina cuando ya ha transcurrido mucho tiempo desde la comisión del delito -en ocasiones, dado el largo período, la víctima ya no existe. Esto es un problema importante pues, (a) si los límites a la magnitud del castigo se determinan a partir de la condición ex ante de la víctima y (b) en muchas ocasiones la aplicación de la pena debe determinarse en circunstancias en que precisamente por la extensión temporal entre el castigo y la comisión del crimen es imposible determinar las condiciones ex ante, entonces (c) en muchas ocasiones es imposible establecer los límites legítimos de la magnitud del castigo. ¿De acuerdo a qué principios determinaríamos los límites de la magnitud legítima del castigo si una condición necesaria de tal límite -la condición ex ante de la víctima- es inasible? La propuesta de Maloberti no responde esta pregunta. ${ }^{13}$

Razón 2: Hay crímenes cuya misma naturaleza impide pensar en la restauración de una posición ex ante (es más, sería obsceno incluso sugerir que la imposición de una pena al agresor puede restaurar en algo esa posición). Ejemplos de esto son la violación, el asesinato, o ciertos daños corporales extremos. En casos como estos o bien asumimos que la pena no tiene límites o bien renunciamos a la idea de que la posición ex ante tiene algo relevante que decirnos para determinar la magnitud de la pena. ${ }^{14}$ Una genuina teoría liberal del castigo debiera inclinarse por esta última alternativa.

Razón 3: Hay crímenes que -bien por ciertas contingencias características del caso particular o bien por la naturaleza misma del crimen- no transforman la posición ex ante de una manera relevante. Algunos de estos casos son los que Joel Feinberg ha considerado en términos del principio de la ofensa y aquellas acciones descritas como harmless wrongdoing (ver Feinberg 1985 y 1987). Por ejemplo, ¿qué posición ex ante debe restituirse por bestialismo público? ${ }^{15} \mathrm{Un}$ caso distinto pero que apunta a una cuestión similar es el caso de Goliat y David. ¿Cuál es el límite del castigo que David debe recibir por su crimen? Pensar que la respuesta a esta pregunta

13 Como sugiero más adelante, el que la teoría de Maloberti no responda esta pregunta no significa que no haya una respuesta posible. En materia civil, por ejemplo, la nulidad del acto jurídico es una de las principales sanciones contempladas en el Código y uno de los efectos de la nulidad es retrotraer a las partes al estado en que se encontraban antes de la celebración del acto nulo. La dificultad en determinar esa posición previa -al respecto, considérese que un juicio de nulidad puede extenderse por mucho tiempo- no ha impedido que la norma siga vigente desde mediados del siglo XIX. Agradezco este punto a John D. Charney.

14 Es necesario enfatizar que mi análisis no intenta afirmar la irrelevancia de la posición ex ante de la victima en toda circunstancia o para todo propósito. Lo que estoy negando es que ese estado ex ante tenga algo relevante que decir en la justificación de los límites del castigo que pueden legítimamente infligirse al ofensor.

15 Estoy aquí asumiendo, osadamente, que el bestialismo es efectivamente un tipo de acción que no genera daño alguno ( $a$ harmless act) pero que efectivamente es un acto malo (a wrongful act). 
depende de la condición ex ante de Goliat -es decir, antes de recibir esos rasguñoses implausible.

Razón 4: Determinar la posición estratégica ex ante de una víctima supone atender a ciertas condiciones subjetivas de la víctima anterior a la comisión del crimen. De esto se sigue que nada impide que por un crimen $\phi$ un sujeto $X$ vea su posición estratégica dañada en un grado distinto que la de un sujeto $Y$ por una misma acción $\phi$. La consecuencia de esto -de acuerdo a la propuesta de Maloberti- es que dos agresores pueden recibir, ceteris paribus, magnitudes distintas de castigo por el mismo tipo de acción $\phi$ realizado contra víctimas distintas cuando estas víctimas ven su posición estratégica dañada de una manera desigual (lo que sucede con X e Y). Supongamos que en otro lugar del universo hay un planeta exactamente igual a aquel en el que David entró en la casa de Goliat -llamémosle tierra gemela- con la única diferencia que en tierra gemela Goliat es un tipo de carácter asustadizo y temeroso. ${ }^{16}$ La posición estratégica ex ante del Goliat de tierra gemela se verá afectada de una manera bien distinta comparada con la del Goliat terrestre a pesar de que todos los otros elementos y circunstancias relevantes de la acción de David terrestre y David de tierra gemela son idénticos. ¿Es correcto afirmar que los límites del castigo que legítimamente podemos imponer a David en tierra gemela deben ser mayores que los imponibles a David terrestre? Responder en positivo supondría una violación del principio de igualdad ante la ley, algo que ninguna teoría liberal del castigo podría darse el lujo de aceptar.

Las consideraciones anteriores debieran llevarnos a pensar que la teoría de Maloberti tiene consecuencias tan indeseables que haríamos mal en considerar esta propuesta -como él sugiere lo hagamos- como una alternativa superior a otras teorías mixtas disponibles. Esas consecuencias son especialmente problemáticas cuando consideramos el contexto en el que ellas ocurren, el del castigo penal, una práctica que demanda niveles de justificación superiores a los de la mayoría de -si no a todas- las otras prácticas disponibles al estado liberal moderno. ${ }^{17}$

Pero, ¿no tendría acaso Maloberti espacio y herramientas para responder a estas objeciones y problemas? Puede ser. Sin embargo, si todo lo dicho hasta este momento es equivocado, o puede ser rebatido por, o acomodado en, la teoría de Maloberti (de hecho me parece que mis Razones 1 y 3 tienen una respuesta más bien simple), aún persistiría un último e importante problema. La sugerencia general de que infligir dolor podría significar algún tipo de restauración en la víctima conlleva aceptar una serie de supuestos perversos (que por lo mismo no deben guiar nuestras políticas públicas) o, simplemente, supone apelar a un nexo misterioso (si no espurio) entre el dolor infligido sobre el agresor y la restauración de la víctima al que al análisis filosófico le conviene evitar. ${ }^{18}$

Obviamente pido esto prestado del experimento de Hilary Putnam (1973).

Para una buena colección de artículos que consideran este punto véase Matravers (1999).

El sufrimiento de dolor se entiende generalmente como una condición necesaria de la práctica punitiva. El locus classicus de esta tesis es Flew (1954), Benn (1958), y Hart (2008a). 
Aquellos supuestos son perversos porque sugieren que la víctima se beneficia del dolor impuesto sobre el ofensor y que es precisamente ese beneficio el que debe llevarnos a infligir dolor-o simplemente justifica la imposición de ese dolor-sobre quien viola algún derecho relevante. Aquel nexo es misterioso porque nada indica que el dolor impuesto sobre un agresor efectivamente sea capaz de generar un estado de cosas semejante al estado de cosas ex ante. Este es un tipo de estrategia que en el derecho anglosajón queda normalmente relegado al tort law o, más generalmente, al derecho civil, donde las compensaciones -y por tanto las restituciones a la parte afectada-son posibles y completas. Por regla general, en el derecho penal tal cosa no es posible y, por lo mismo, la justificación del castigo y sus límites en estos términos genera problemas serios que cualquier teoría plausible debe evitar.

Las dificultades consideradas aquí son en gran medida consecuencia del alejamiento del modelo de Maloberti de ciertos elementos centrales a la concepción lockeana del castigo, tal y como lo presenté en la primera parte de este artículo. La concepción lockeana remueve de la esfera meramente individual y privada la aplicación de cargas punitivas contra quienes violan nuestros derechos y ubica este poder en el Estado. En efecto, para Locke el Estado se define, parcial pero significativamente, en términos de la legitimidad que éste posee para imponer cargas retributivas a los individuos que violan normas relevantes. La posición de Maloberti, en cambio, relativiza ese movimiento fundamentalmente político y reivindica la mantención y ejercicio del derecho natural a castigar. Como mostré anteriormente, tal reivindicación no es composible con la idea lockeana de la práctica del castigo como fundante del Estado y condición necesaria de la protección del derecho natural de todos los individuos a la propiedad. ${ }^{19}$ La prescindencia del Estado en la determinación del castigo, sumada a la importancia que este modelo le asigna a la condición ex ante de la víctima, conlleva una serie de dificultades como las que he señalado en esta última sección (dificultades que son independientes y adicionales a las consideradas como Objeción tipo I): indeterminación de los límites legítimos de la magnitud del castigo merecido, imposibilidad de determinar tales límites dada la naturaleza de los actos castigados, transgresión ilegítima del principio de igualdad ante la ley. Toda genuina teoría liberal del castigo debe minimizar, si no evitar, cada una de estas dificultades.

\section{CONCLUSIÓN}

La teoría del castigo de Locke es liberal porque se funda en ciertos principios y valores individualistas. En efecto, una teoría del castigo que no tome en serio el valor del individuo difícilmente podría entenderse como una teoría lockeana del castigo. En la segunda parte de este trabajo he intentado mostrar que la propuesta de Nicolás Maloberti no sigue este principio lockeano básico. La sugerencia de que el individuo debe mantener su derecho a efectuar/actualizar su derecho a amenazar a otros y, en consecuencia, mantener su derecho natural a castigar en el contexto de una comunidad política, es algo que ninguna propuesta genuinamente lockeana podría defender. En 
la tercera parte del artículo, en cambio, he defendido la idea de que la propuesta de Maloberti sufre de una serie de problemas importantes que cuestionan la coherencia y conveniencia de su teoría.

Cualquier teoría liberal del castigo debe tomar el valor del individuo en serio. Como indica Maloberti, esto significa que debe permitirse que las personas tengan la libertad de vivir sus vidas de acuerdo a sus propias elecciones (cf. Maloberti, 2011: 32). Para que esto ocurra, una condición necesaria es que la teoría del castigo que guíe nuestras prácticas se someta a principios adecuadamente delineados. Entre otras cosas, esto exige que una teoría liberal debe proveer de mecanismos normativos generalmente suficientes para establecer las magnitudes punitivas que legítimamente pueden imponerse a un individuo ofensor. Asimismo, esa teoría debe someterse sin excepción al principio de igualdad ante la ley. Parte de mis argumentos han intentado mostrar que la propuesta de Maloberti falla en ambas cuestiones.

Las consecuencias de la consideración descuidada de estos principios y mecanismos van en contra de uno de los objetivos más caros a cualquier teoría liberal del derecho. Es justamente por esto que me parece importante mostrar que la propuesta de Maloberti no es ni lockeana ni liberal. En palabras de H.L.A. Hart, un defensor conspicuo de una teoría liberal del castigo y del derecho, el derecho penal -y no hay razón para no agregar aquí también al derecho en general- debe articularse de manera de "reconocer que el destino de un hombre debe depender de sus decisiones" (Hart, 2008b: 182); así, cuando el derecho es lo que debe ser, se transforma en un mecanismo diseñado para maximizar la eficacia para determinar y predecir el futuro a partir de las decisiones individuales adecuadamente informadas (cf. Hart, 2008c: 46). Cualquier teoría que por falta de principios suficientes o adecuados haga peligrar la predictibilidad de las consecuencias de nuestras acciones dentro de la comunidad política es una teoría que cae en falta de cara al valor del individuo. Aquella teoría no puede ser una teoría liberal del castigo.

\section{REFERENCIAS}

Benn, Stanley. 1958. "An Approach to the Problems of Punishment". Philosophy 33 (127): 325-341.

Blackstone, William. 1770. Commentaries on the Laws of England, 4 volúmenes. Dublin: John Exshaw int. al. Duff, Antony. 2001. Punishment, Communication and Community. New York: Oxford University Press.

Feinberg, Joel. 1985. Offence to Others. New York: Oxford University Press.

Feinberg, Joel. 1987. Harmless Wrongdoing. New York: Oxford University Press.

Flew, Antony. 1954. "The Justification of Punishment", Philosophy 29 (111): 291-307.

Hart, Herbert L.A. 2008a. "Prolegomenon to the Principles of Punishment", en Punishment and Responsibility (2nd. ed.). Oxford: Oxford University Press, pp. 1-27.

Hart, Herbert L.A. 2008b. "Punishment and the Elimination of Responsibility", en Punishment and Responsibility (2nd. ed.). Oxford: Oxford University Press, pp. 158-185.

Hart, Herbert. L.A. 2008c. "Legal Responsibilities and Excuses", en Punishment and Responsibility (2nd. ed.). Oxford: Oxford University Press, pp. 28-53.

von Hirsch, Andrew. 1993. Censure and Sanctions. Oxford: Oxford University Press.

Hurka, Thomas. 2003. "Desert: Individualistic and Holistic", en S. Olsaretti (ed.), Desert and Justice. Oxford: Oxford University Press, pp. 45-68.

Lamond, Grant. 2007. "What is a crime?". Oxford Journal of Legal Studies 27 (4): 609-632. 
Locke, John. 2003. Two Treatises of Government and A Letter Concerning Tolerance, I. Shapiro (ed.). London: Yale University Press.

Maloberti, Nicolás. 2011. "Disuasión y Castigo Desde una Perspectiva Lockeana". Revista de Ciencia Politica 31 (1): 29-46.

Marshall, Sandra \& Duff, Antony. 1998. "Criminalisation and Sharing Wrongs". Canadian Journal of Law and Jurisprudence 11 (1): 7-22.

Matravers, Matt. (ed.). 1999. Punishment and Political Theory. Oxford: Hart.

Putnam, Hilary. 1973. "Meaning and Reference". The Journal of Philosophy 70 (19): 699-711.

Quinn, Warren. 1985. "The Right to Threaten and the Right to Punish". Philosophy and Public Affairs 14 (4): 327-373.

Shue, Henry. 1996. Basic Rights: Subsistence, Affluence, and US Foreign Policy (2nd. ed.). Princeton: Princeton University Press.

Steiner, Hillel. 1994. An Essay on Rights. Oxford: Oxford University Press.

Alfonso Donoso. Profesor Asistente del Instituto de Ciencia Política de la Pontificia Universidad Católica de Chile. Sus áreas principales de investigación en filosofía política son la justicia retributiva, las teorías normativas de la autodeterminación política y los fundamentos de la coacción legítima. E-mail: aldonoso@uc.cl. 